\section{Original Article \\ Dermatology}

Check for updates

\section{OPEN ACCESS}

Received: Sep 16, 2018

Accepted: Apr 8, 2019

Address for Correspondence:

Sung Yul Lee, MD, PhD

Department of Dermatology, Soonchunhyang

University Cheonan Hospital, Soonchunhyang

University College of Medicine, 31

Sooncheonhyang 6-gil, Dongnam-gu,

Cheonan 31151, Republic of Korea.

E-mail: dermsung@schmc.ac.kr

Chun Wook Park, MD, PhD

Department of Dermatology, Kangnam Sacred

Heart Hospital, Hallym University College of

Medicine, 1 Singil-ro, Yeongdeungpo-gu,

Seoul 07441, Korea.

E-mail: dermap@daum.net

*Jung Eun Kim and Bo Young Chung

contributed equally to this work.

(c) 2019 The Korean Academy of Medical

Sciences.

This is an Open Access article distributed under the terms of the Creative Commons Attribution Non-Commercial License (https:// creativecommons.org/licenses/by-nc/4.0/) which permits unrestricted non-commercial use, distribution, and reproduction in any medium, provided the original work is properly cited.

ORCID iDs

Jung Eun Kim (D)

https://orcid.org/0000-0002-8399-8456 Bo Young Chung (iD

https://orcid.org/0000-0002-2795-0140

Chang Yoon Sim (D)

https://orcid.org/0000-0001-6622-8487

\title{
Clinicopathologic Features and Prognostic Factors of Primary Cutaneous Melanoma: a Multicenter Study in Korea
}

\author{
Jung Eun Kim $\left(\mathbb{D},{ }^{1 *}\right.$ Bo Young Chung $\mathbb{D},{ }^{2 *}$ Chang Yoon Sim $\mathbb{1},{ }^{1}$ A Young Park $\mathbb{1},{ }^{1}$ \\ Jong Suk Lee $\mathbb{B},{ }^{1}$ Kyu Uang Whang $\mathbb{D},{ }^{3}$ Young Lip Park $\mathbb{1},{ }^{4}$ Hye One Kim $\mathbb{D},{ }^{2}$ \\ Chun Wook Park $\mathbb{( D},{ }^{2}$ and Sung Yul Lee ${ }^{1}{ }^{1}$
}

'Department of Dermatology, Soonchunhyang University Cheonan Hospital, Soonchunhyang University College of Medicine, Cheonan, Korea

${ }^{2}$ Department of Dermatology, Kangnam Sacred Heart Hospital, Hallym University College of Medicine, Seoul, Korea

${ }^{3}$ Department of Dermatology, Soonchunhyang University Seoul Hospital, Soonchunhyang University College of Medicine, Seoul, Korea

${ }^{4}$ Department of Dermatology, Soonchunhyang University Bucheon Hospital, Soonchunhyang University College of Medicine, Bucheon, Korea

\section{ABSTRACT}

Background: Malignant melanoma is a cutaneous malignancy with a high mortality rate and high potential for metastases. Detailed information on the clinicopathologic characteristics and prognostic factors of cutaneous melanoma is currently limited in Korea. This study aimed to identify the epidemiological and clinicopathologic characteristics of primary cutaneous melanoma in Korean patients, and to assess which prognostic variables could influence both the development of metastases in primary cutaneous melanoma and overall survival (OS).

Methods: A total of 261 patients diagnosed with primary cutaneous melanoma in seven medical centers between 1997 and 2017 were retrospectively investigated with regard to clinical presentation, localization of the tumor, histopathologic subtype, and survival time. Results: The nodular histologic subtype, ulceration, and Breslow thickness were significantly associated with the development of metastasis; and overweight and obesity (body mass index > 23) were significantly associated with increased Breslow thickness. The location of the metastases appeared to influence OS: brain metastases were associated with the highest risk of death, followed by gastrointestinal, lung, and extra-regional lymph node metastases. Conclusion: In this study, tumor thickness, nodular histologic subtype, and ulceration predicted metastatic spread of primary cutaneous melanoma. In addition, OS was associated with the location of metastases. Obesity was related to the prognosis of primary cutaneous melanoma. Clinicians should bear these findings in mind when forming a diagnosis because of the risk of a poor prognosis.

Keywords: Melanoma; Neoplasm Metastasis; Obesity; Skin Neoplasms; Survival 
A Young Park (iD)

https://orcid.org/0000-0002-9775-0654 Jong Suk Lee (iD

https://orcid.org/0000-0002-6554-7598

Kyu Uang Whang (iD

https://orcid.org/0000-0003-3653-6408

Young Lip Park iD

https://orcid.org/0000-0002-6532-3156

Hye One Kim (iD)

https://orcid.org/0000-0001-5846-0008

Chun Wook Park iD

https://orcid.org/0000-0003-4512-8668

Sung Yul Lee (iD)

https://orcid.org/0000-0002-6995-4561

Funding

This research was partly supported by

the Soonchunhyang University Research

Fund, Hallym University Research

Fund 2017 (HURF-2017-52) and the

National Research Foundation of Korea

(NRF-2018R1C1B5042271and NRF-

2018R1C1B6007998).

Disclosure

The authors have no potential conflicts of interest to disclose.

Author Contributions

Conceptualization: Kim JE, Chung BY, Lee SY, Park CW. Data curation: Sim CY, Lee JS. Formal analysis: Kim HO. Methodology: Whang KU,

Park YL. Writing - original draft: Sim CY, Kim JE, Chung BY. Writing - review \& editing: Lee SY, Park CW.

\section{INTRODUCTION}

Malignant melanoma (MM) is one of the most aggressive known skin tumors due to its frequent metastases, high mortality rate, and resistance to available therapies. Worldwide, 160,000 new melanoma cases are diagnosed each year and the incidence of MM has increased recently. ${ }^{1}$ The incidence of particular subtypes of $\mathrm{MM}$ varies according to the type of skin; superficial spreading melanoma (SSM) is the most common type in Caucasians, while acral lentiginous melanoma (ALM) is most commonly reported in Asians. ${ }^{2-5}$

MM is a rare disease in Asians because of the protection conferred by pigmented skin, but the incidence shows an upward trend in Koreans. ${ }^{6-8}$ However, information on the clinicopathologic characteristics and prognostic factors of cutaneous melanoma is limited in Korea.

In this study, primary cutaneous melanoma cases diagnosed in seven centers over the course of 21 years were investigated retrospectively. The objective of this study was to describe the epidemiological and clinicopathologic characteristics of primary cutaneous melanoma in Korean patients and to identify the clinicopathologic variables associated with the clinical course of primary cutaneous melanoma, including metastases, and overall survival (OS).

\section{METHODS}

\section{Patient selection and study design}

The electronic medical records of all primary cutaneous melanoma cases diagnosed between 1997 and 2017 in seven medical centers (Hallym University Kangdong Sacred Heart Hospital, Hallym University Dongtan Sacred Heart Hospital, Hallym University Kangnam Sacred Heart Hospital, Hallym University Chuncheon Sacred Heart Hospital, Soonchunhyang University Seoul Hospital, Soonchunhyang University Bucheon Hospital, and Soonchunhyang University Cheonan Hospital) were retrospectively reviewed. All cases were confirmed as primary cutaneous melanoma after histopathologic testing, by a dermatologist and pathologist. Non-cutaneous MM was excluded.

Data on the following variables were collected and analyzed: age, gender, body mass index (BMI), site of primary lesion, histologic subtype, Breslow tumor thickness, Clark level, presence of ulceration, metastasis (presence or absence, and first metastatic site), and period of survival. Patients were categorized into two different groups according to their age at diagnosis: 0-59 years and 60 years or older. Primary cutaneous melanoma was classified into four groups according to its anatomical location: head and neck, hand and foot, extremities, and trunk. The histologic subtype was categorized based on the World Health Organization classification: SSM, nodular melanoma (NM), ALM, and lentigo maligna melanoma (LMM). According to the American Joint Committee on Cancer (AJCC) staging system, tumor thickness and invasion were assessed by the staging systems of Breslow and Clark, respectively. The survival time was defined as the interval between the date of diagnosis of the primary cutaneous melanoma and the registered date of death or the date of the last consultation. We defined and classified these variables based on previous reports about malignant melanoma. ${ }^{9-14}$

\section{Statistical analyses}

The Kaplan-Meier method and multivariate Cox's proportional hazards analysis were used. The associations were summarized by using hazard ratios (HRs), odds ratio (OR) and 95\% 
confidence intervals (CIs). OS was calculated by the Kaplan-Meier method with a CI of 95\%. Differences were considered significant at $P<0.05$. Statistical analyses were performed using SPSS for Windows statistical software package (version 21.0; SPSS Inc., Chicago, IL, USA).

\section{Ethics statement}

This study was approved by the Institutional Review Boards (IRBs) of Soonchunhyang University Hospital Cheonan and Hallym University Kangnam Sacred Heart Hospital (IRB No. 2017-09-006-001 and 2017-10-011, respectively). Informed consent was not obtained because this was a retrospective study using clinical data.

\section{RESULTS}

Between 1997 and 2017, a total of 261 patients were diagnosed with primary cutaneous melanoma in seven medical centers. All electronic medical records were retrieved and reviewed. The men-to-women ratio was 1:1.3. The mean age of the patients was $62 \pm 15.8$ years (range, 21-99 years). The median follow-up period for the entire cohort was 18 months (range, 1-210 months). The anatomic distribution and histopathologic features of the melanomas in our study are shown in Table 1 . We compared clinicopathologic features of our patients with previous reports (Table 2). $15-18$

Table 1. Clinical and histopathologic features of 261 primary cutaneous melanomas

\begin{tabular}{|c|c|c|c|c|}
\hline CM characteristics & Total & Young people $^{a}$ & Elderly $^{\mathrm{b}}$ & $P$ value \\
\hline Location & & & & 0.111 \\
\hline Extremities & 41 (15.7) & $22(21.0)$ & $15(9.6)$ & \\
\hline Trunk & $46(17.6)$ & $21(20.0)$ & $25(16.0)$ & \\
\hline Head and neck & $58(22.2)$ & $20(19.0)$ & $40(25.6)$ & \\
\hline Hand and foot & $116(44.4)$ & $42(40.0)$ & $76(48.7)$ & \\
\hline Total & $261(100.0)$ & 105 (100.0) & 156 (100.0) & \\
\hline Type & & & & 0.762 \\
\hline SSM & $19(7.3)$ & $10(9.5)$ & $9(5.8)$ & \\
\hline NM & $25(9.6)$ & $11(10.5)$ & $14(9.0)$ & \\
\hline ALM & $115(44.1)$ & $43(41.0)$ & $72(46.2)$ & \\
\hline LMM & 5 (1.9) & $2(1.9)$ & $3(1.9)$ & \\
\hline Melanoma NOS & $97(37.2)$ & 39 (37.1) & $58(37.2)$ & \\
\hline Total & $261(100.0)$ & 105 (100.0) & 156 (100.0) & \\
\hline Breslow thickness & & & & 0.811 \\
\hline$\leq 1.00 \mathrm{~mm}$ & $8(3.1)$ & $4(3.8)$ & $4(2.6)$ & \\
\hline $1.01-2.00 \mathrm{~mm}$ & $72(27.6)$ & $29(27.6)$ & $43(27.6)$ & \\
\hline $2.01-4.00 \mathrm{~mm}$ & 45 (17.2) & $22(21.0)$ & $23(14.7)$ & \\
\hline$>4.00 \mathrm{~mm}$ & $36(13.8)$ & $15(14.3)$ & $21(13.5)$ & \\
\hline Unknown & $100(38.3)$ & $35(33.3)$ & 65 (41.7) & \\
\hline Total & 261 (100.0) & 105 (100.0) & 156 (100.0) & \\
\hline Clark & & & & 0.219 \\
\hline 1 & $79(30.3)$ & $32(30.5)$ & $47(30.1)$ & \\
\hline II & $33(12.6)$ & 15 (14.3) & $18(11.5)$ & \\
\hline III & $43(16.5)$ & $20(19.0)$ & $23(14.7)$ & \\
\hline IV & 45 (17.2) & $12(11.4)$ & 33 (21.2) & \\
\hline V & $2(0.8)$ & $0(0)$ & $2(1.3)$ & \\
\hline Unknown & $59(22.6)$ & $26(24.8)$ & 33 (21.2) & \\
\hline Total & $261(100.0)$ & 105 (100.0) & $156(100.0)$ & \\
\hline
\end{tabular}


Table 2. Clinical and histopathological features of melanoma patients in previous reports

\begin{tabular}{|c|c|c|c|c|c|c|c|}
\hline Study (year) & $\begin{array}{c}\text { Total patient } \\
\text { number }\end{array}$ & $\begin{array}{c}\text { Gender } \\
\text { (men:women) }\end{array}$ & $\begin{array}{l}\text { Mean age } \\
\text { at diagnosis }\end{array}$ & $\begin{array}{c}\text { Frequency of } \\
\text { melanoma subtype }\end{array}$ & $\begin{array}{l}\text { Most common } \\
\text { location }\end{array}$ & $\begin{array}{l}\text { Most common/Mean } \\
\text { Breslow depth, mm }\end{array}$ & $\begin{array}{l}\text { Presence } \\
\text { of ulcer, \% }\end{array}$ \\
\hline Park et al.15 (2007) & 97 & $1: 1.2$ & 59.7 & $A L M>N M>S S M=L M \& L M M$ & Feet & $2.01-4(22.2 \%)$ & 45.6 \\
\hline Jang et al. ${ }^{16}$ (2014) & 206 & $1: 1.03$ & 60 & $\begin{array}{c}\mathrm{ALM}>\mathrm{MM}>\mathrm{NM}>\mathrm{SSM}> \\
\mathrm{LMM}>\end{array}$ & Acral & 4.45 & 27.7 \\
\hline Nam et al. 17 (2015) & 100 & $1: 1.8$ & 55 & $\mathrm{ALM}>\mathrm{NM}>\mathrm{SSM}>\mathrm{LMM}$ & Feet & $\geq 4.01(32 \%)$ & - \\
\hline Lee et al.18 (2018) & 122 & $1.26: 1$ & 61.2 & $\mathrm{ALM}>\mathrm{SSM}>\mathrm{NM}$ & - & $>1$ to $\leq 2(39.3 \%)$ & 29.5 \\
\hline Current study & 261 & $1: 1.3$ & 62 & $\mathrm{ALM}>\mathrm{NM}>\mathrm{SSM}>\mathrm{LMM}$ & Hand and foot & $1.01-2.00(27.6 \%)$ & 41.0 \\
\hline
\end{tabular}

$\mathrm{ALM}=$ acral lentiginous melanoma, NM = nodular melanoma, SSM = superficial spreading melanoma, LM= lentigo maligna, $\mathrm{LMM}=$ lentigo maligna melanoma, MM = mucosal melanoma

The 1-, 2-, and 5-year OS for the entire group was $63.3 \%, 55.4 \%$, and $51.9 \%$, respectively. The mean survival time was 83.9 months (95\% CI, 64.7-103.1) and the median OS was 65.4 months (95\% CI, 13.5-117.4) (Table 3). A total of 109 patients (41.8\%) had metastasis of the melanoma in the brain, gastrointestinal tract, liver, lung, or distant lymph node at diagnosis or during the follow-up period. The first location of metastases was the brain in $20(7.7 \%)$, liver and gastrointestinal tract in $33(12.6 \%)$, lung in $31(11.9 \%)$, and extra-regional distant lymph node plus others in 25 (9.6\%) patients (Table 4). The median OS from the time of detection of any metastasis was only 7.8 months ( $95 \%$ CI, 6.1-9.4) and the mean survival was 9.9 months (95\% CI, 8.1-11.7). The 1-year OS of stage IV patients was $28.6 \%$ and the 2-year OS was $14.3 \%$. By Cox regression, the median OS is showed to have increased 17.7-fold without metastasis $(P<0.001)$. We found that MM patients with brain metastasis had the lowest median OS, of only 2.79 months ( $95 \%$ CI, 0.69-4.89), followed by patients with metastases in the liver and gastrointestinal tract (median OS of 5.96 months; 95\% CI, 4.39-7.53) and lung metastases (median OS, 7.50 months, 95\% CI, 3.42-11.58) (Table 4 and Fig. 1).

According to the Kaplan-Meier method and Cox's multivariate analysis, the following variables were risk factors for the development of metastasis of primary cutaneous melanoma: NM type $(P=0.016)$, Breslow thickness $>2.00 \mathrm{~mm}(P<0.01)$, and ulceration $(P<0.001)$ (Table 5 and Figs. 2-4). Multivariate analysis of the clinicopathological variables associated with increased Breslow thickness was also performed. Patients whose data were not fully investigated were excluded. Gender and histologic subtype were not significantly associated with Breslow thickness $(P>0.05)$. As age increased, so too did the Breslow

Table 3. OS rate and median OS

\begin{tabular}{lc}
\hline Survival rate & $\%$ \\
\hline 1-yr survival rate & 63.3 \\
2-yr survival rate & 55.4 \\
5-yr survival rate & 51.9 \\
Median OS, mon & 65.4 \\
\hline
\end{tabular}

OS = overall survival.

Table 4. Distribution of first metastatic site and OS rate for stage IV patients according to first metastatic site

\begin{tabular}{|c|c|c|c|c|c|}
\hline Variables & Brain & GI & Lung & Distant LN, other & No metastasis \\
\hline No. (\%) & $20(7.7)$ & $33(12.6)$ & 31 (11.9) & $25(9.6)$ & $152(58.2)$ \\
\hline \multicolumn{6}{|c|}{ OS rate for stage IV patients according to first metastatic site } \\
\hline 3 mon & 37.0 & 71.4 & 75.0 & 83.6 & 99.3 \\
\hline 6 mon & 0.0 & 43.7 & 55.0 & 75.1 & 99.3 \\
\hline 9 mon & 0.0 & 19.4 & 30.0 & 62.2 & 98.2 \\
\hline $1 \mathrm{yr}$ & 0.0 & 4.9 & 25.0 & 51.4 & 96.9 \\
\hline $2 \mathrm{yr}$ & 0.0 & 0.0 & 0.0 & 16.1 & 95.6 \\
\hline
\end{tabular}

OS = overall survival, $\mathrm{GI}=$ gastrointestine, $\mathrm{LN}=$ lymph node. 


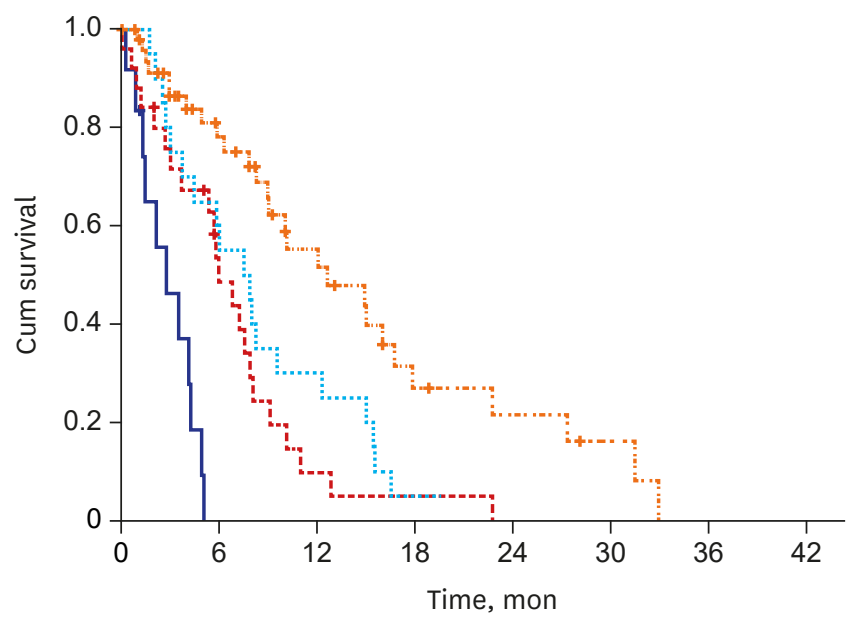

Fig. 1. Kaplan-Meier overall survival for American Joint Committee on Cancer stage IV cutaneous melanoma patients depending on the first metastatic site. Brain metastasis (blue line), liver and gastrointestinal tract metastasis (red line), lung metastasis (skyblue line), and distant lymph node metastasis and others (orange line).

Table 5. Cox multivariate analysis for metastasis

\begin{tabular}{lcc}
\hline Categories & $\mathrm{HR}(95 \% \mathrm{Cl})$ & \\
\hline Ulcer & Reference & \\
$\quad \begin{array}{l}\text { No ulceration } \\
\text { Ulceration }\end{array}$ & $24.30(8.71-67.80)$ & \\
Gender & Reference & \\
$\quad$ Men & $1.96(0.80-4.76)$ & 0.139 \\
Women & & \\
Breslow thickness $(\mathrm{mm})$ & Reference & \\
$\leq 1.00$ & $3.07(0.95-9.94)$ & 0.060 \\
$1.01-2.00$ & $17.08(4.78-61.07)$ & $<0.001$ \\
$2.01-4.00$ & $47.70(12.04-188.95)$ & \\
$>4.00$ & & 0.001 \\
Melanoma subtype & Reference & \\
SSM & $27.29(1.87-398.55)$ & 0.016 \\
NM & $10.87(0.918-128.59)$ & - \\
ALM & - & 0.007 \\
LMM & $33.85(2.68-427.89)$ & \\
Melanoma NOS & & \\
\hline
\end{tabular}

$\mathrm{HR}=$ hazard ratio, $\mathrm{Cl}=$ confidence interval, $\mathrm{SSM}=$ superficial spreading melanoma, $\mathrm{NM}=$ nodular melanoma, $\mathrm{ALM}=$ acral lentiginous melanoma, LMM = lentigo maligna melanoma, NOS = not otherwise specified.

thickness, but this association did not reach statistical significance. However, overweight and obesity (BMI $>23$ ) was significantly associated with increased Breslow thickness $(P<0.01)$. (Table 6). Thus, we additionally evaluated the direct effects of overweight and obesity (BMI $>23$ ) on the development of metastasis and OS. The risk associated with the development of metastasis was significant with an OR of 2.10 (95\% CI, 1.2-3.6). Moreover, overweight and obesity (BMI > 23) was also significantly associated with shorter OS $(P=0.033)$.

\section{DISCUSSION}

MM is a malignant tumor originating from melanocytes of the skin and other organs, and is characterized by a high risk of metastasis and death. This study demonstrated the epidemiologic and clinicopathologic characteristics of primary cutaneous melanoma in a 


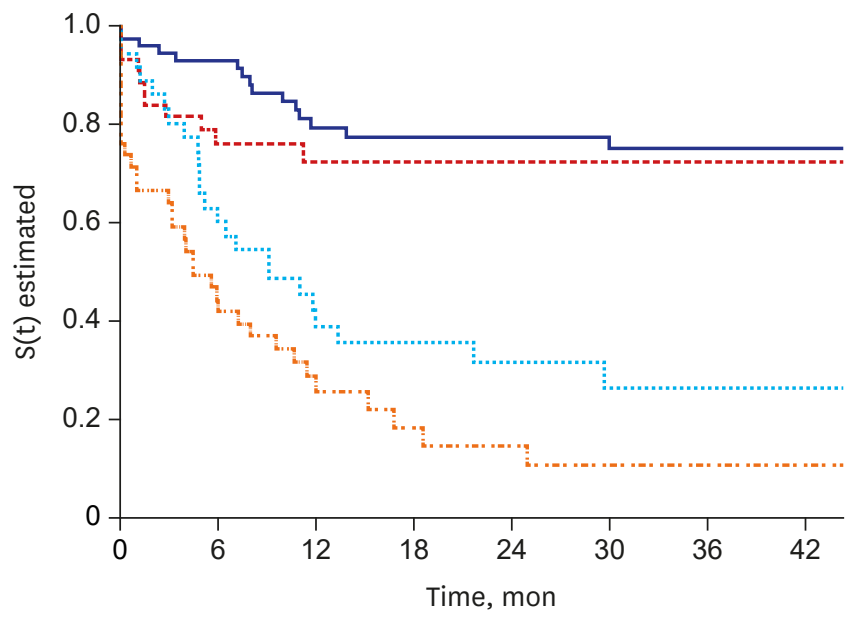

Fig. 2. Kaplan-Meier curves showing the time of metastasis in patients with primary cutaneous melanoma according to Breslow thickness. Breslow thickness $<1 \mathrm{~mm}$ (blue line), Breslow thickness $=1.01-2.00 \mathrm{~mm}$ (red line), Breslow thickness $=2.01-4.00 \mathrm{~mm}$ (skyblue line), and Breslow thickness $>4 \mathrm{~mm}$ (orange line) .

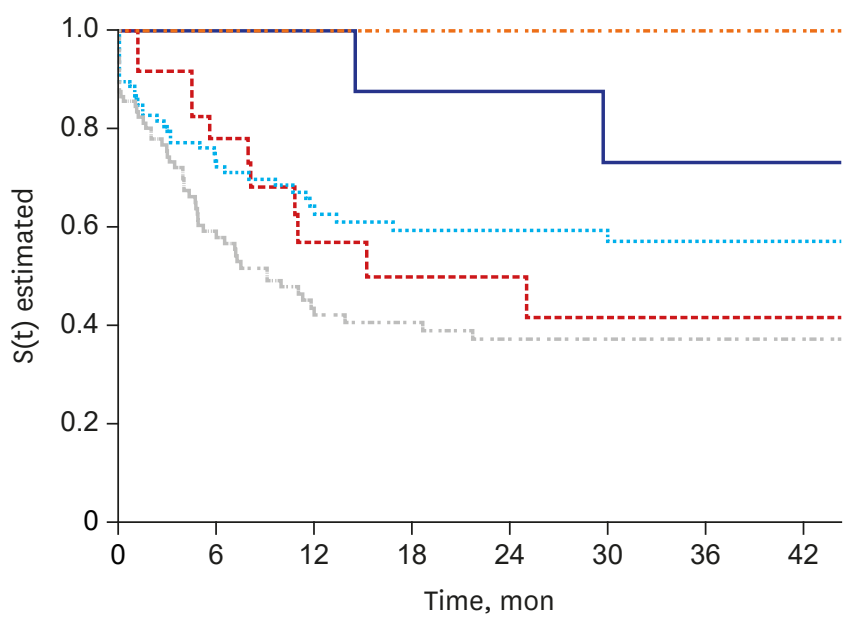

Fig. 3. Kaplan-Meier curves showing the time of the metastasis in patients with primary cutaneous melanoma according to the histologic subtype. Lentigo maligna (orange line), superficial spreading (blue line), acral (skyblue line), nodular (red line), and not otherwise specified (gray line).

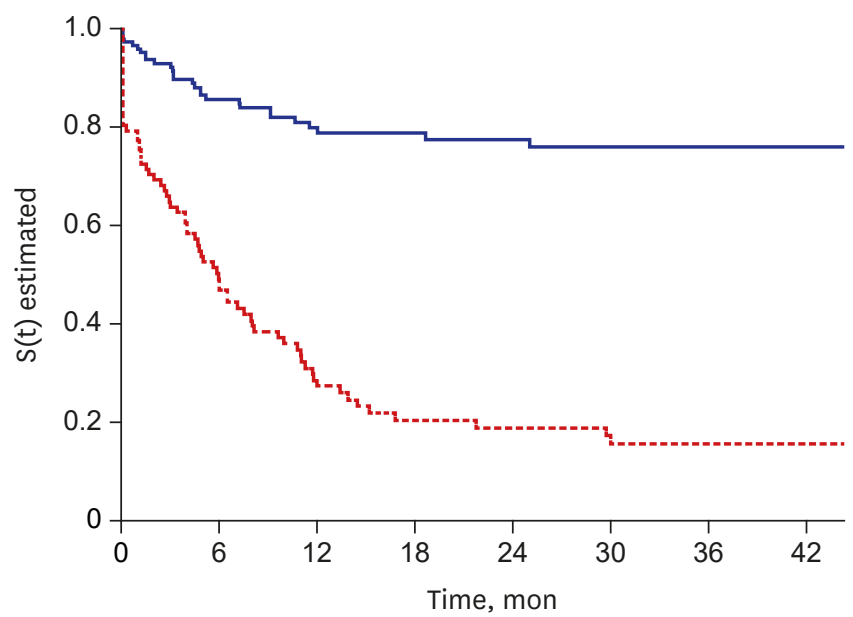

Fig. 4. Kaplan-Meier curves showing the time of metastasis in patients with primary cutaneous melanoma according to the presence of ulceration. No ulceration (blue line), and ulceration (red line). 
Table 6. Cox multivariate analysis of clinicopathologic variables associated with Breslow thickness

\begin{tabular}{lcc}
\hline Categories & $\mathrm{HR}(95 \% \mathrm{Cl})$ & \\
\hline Age $^{\mathrm{a}}$ & Reference & \\
$0-59$ & $1.72(0.95-3.11)$ & 0.07 \\
$60-101$ & & \\
Gender ${ }^{\mathrm{a}}$ & Reference & \\
$\quad$ Men & $0.87(0.43-1.74)$ & 0.69 \\
Women & & \\
BMI $^{\mathrm{a}}$ & Reference & 0.14 \\
13.00-20.00 & $3.30(0.68-16.05)$ & 0.001 \\
$20.01-23.00$ & $16.42(3.37-80.08)$ & 0.001 \\
$23.01-25.00$ & $25.62(5.44-120.65)$ & \\
$25.01-37.00$ & & 0.08 \\
Melanoma subtype & Reference & 0.19 \\
SSM & $5.37(0.83-34.81)$ & 0.08 \\
NM & $3.06(0.59-15.97)$ & 0.03 \\
ALM & $17.47(0.68-49.10)$ & \\
LMM & $6.57(1.23-35.03)$ & \\
Melanoma NOS & &
\end{tabular}

$\mathrm{HR}=$ hazard ratio, $\mathrm{Cl}=$ confidence interval, $\mathrm{BMI}=$ body mass index, $\mathrm{SSM}=$ superficial spreading melanoma, $\mathrm{NM}=$ nodular melanoma, $\mathrm{ALM}=$ acral lentiginous melanoma, LMM = lentigo maligna melanoma, NOS $=$ not otherwise specified.

${ }^{\text {a }}$ Categorized in three groups.

number of centers in Korea. Prognostic clinicopathologic variables potentially related to the disease course of MM, in terms of the development of metastases and OS, were also evaluated.

In our study, the most common site of cutaneous melanoma was the hand and foot (44.4\%), and the most common histopathologic subtype was ALM (44.1\%). These results agree with those of previous studies of melanoma in Korea and other Asian countries, which also described the most common site as hand and foot.12,19-21 In terms of histologic subtype, a previous study of melanoma in Korea also found that ALM accounted for more than $70 \%$ of all cases. ${ }^{22}$ In addition, ALM was the most common type of melanoma in a Chinese study, accounting for nearly half of all cases, while the sum of the incidences of NM, SMM, and LMM was less than half the incidence of ALM. ${ }^{23}$ Regardless of type, $41.4 \%$ of the melanoma patients in the present study had AJCC stage IV disease. Among them, 42 patients $(16.1 \%)$ had stage IV ALM. Jung et al. ${ }^{24}$ noted the proportion of Korean ALM patients presenting with stage IV disease and showed that $5.4 \%$ of ALM patients had metastases. Data from Chinese populations showed that stage IV ALM represented $2.8 \%$ of all cases. ${ }^{25}$ In the present study, the prevalence of AJCC stage IV ALM was higher than in other Asian studies. We consider this result to be due to the fact that ALM is usually detected at a later stage than other types of melanoma in Asians and that all involved medical centers were tertiary referral hospitals, such that patients might have been more likely to have severe disease. ${ }^{2}$

The development of distant metastases is known to be a serious problem, with melanoma being associated with a high mortality rate. In the present study, Cox's regression analysis showed that the median OS rate increased 17.7-fold without metastasis $(P<0.001)$. The median OS for patients with metastases was 7.8 months (95\% CI, 6.1-9.5 months), which was similar to another large study of melanoma, in which the mean median survival time was 7-8 months for patients with metastases. ${ }^{26}$ The prognosis of MM depends on the site of metastasis. ${ }^{27}$ The mean OS rate was reported to be 4 months for liver, brain, and bone metastases, 8 months for lung metastases, and 12.5 months for gastrointestinal metastases. ${ }^{27}$ When classified according to metastasis site, the lowest OS was seen in the brain metastasis group. The present study found that MM patients with brain metastases had the lowest 
median OS, of only 2.79 months. The 5 -year survival rate of patients with brain metastases was $0 \%$, while in other clinical trials the estimated 5-year survival was $0 \%-5 \% .28,29$ In an autopsy study, $75 \%$ of patients who died of MM had brain metastases. 30

In the current study, nodular histologic subtype, ulceration, and the Breslow thickness of the primary cutaneous melanoma were significantly associated with the development of metastasis. Homolak et al. ${ }^{11}$ retrospectively evaluated the association between various predictor variables and sentinel lymph node biopsy (SLNB) outcomes (positive SLNB and metastatic development) in 844 patients with primary cutaneous melanoma. They showed results consistent with those of the present study, where the main predictors of metastatic spread were Breslow thickness, nodular-type melanoma, and ulceration. A previous study in Australia also reported that the rapid growth of primary cutaneous melanomas was associated with tumor thickness and aggressive histologic features. NM grew four times faster than either SSM or LMM. ${ }^{31}$ Our study also showed that the Breslow thickness, development of metastasis and shorter OS were related to excess body weight. Obesity has been considered a risk factor for many types of cancer, including those of the endometrium, colon, esophagus, breast, kidney, gallbladder, pancreas, prostate, and thyroid. ${ }^{32}$ Epidemiological studies found a relationship between excess body weight and the risk of developing melanoma. ${ }^{32,33}$ Retrospective European studies found that excess body weight was associated with increased Breslow thickness. 34,35 Interestingly, the present study found that excess body weight (BMI > 23) was associated with increased Breslow thickness in a Korean population. Potential mechanisms of melanoma growth due to obesity are as follows: 1) chronic hyperinsulinemia; 2) high plasma leptin level; 3) caveolin-1 expression; and 4) low serum vitamin D level. ${ }^{36}$ Excess body weight is associated with hyperinsulinemia, insulin resistance, and high insulin-like growth factor-1 levels, which lead to tumor growth via stimulation of angiogenesis and inhibition of apoptosis. ${ }^{37}$ Leptin, a cytokine secreted by adipose tissue, has direct mitogenic activity and may accelerate melanoma tumor growth. ${ }^{38}$ A previous study analyzed the overexpression of caveolin-1, a scaffolding protein involved in tumor proliferation, and fatty acid synthase, an enzyme implicated in the promotion of melanoma cells. ${ }^{39} \mathrm{BMI}$ is inversely related to serum vitamin $\mathrm{D}$, which is important in both the risk and prognosis of cutaneous melanoma. 40

This study had limitations. The data were collected retrospectively and extracted from previous records; in some cases, the desired information, such as Breslow thickness and histopathologic subtype, was missing because diagnostic protocols and medical record formats differed among the hospitals.

\section{REFERENCES}

1. Usher-Smith JA, Emery J, Kassianos AP, Walter FM. Risk prediction models for melanoma: a systematic review. Cancer Epidemiol Biomarkers Prev 2014;23(8):1450-63. PUBMED | CROSSREF

2. Kim SY, Yun SJ. Cutaneous melanoma in Asians. Chonnam Med J 2016;52(3):185-93. PUBMED | CROSSREF

3. Uysal-Sonmez O, Tanriverdi O, Esbah O, Uyeturk U, Helvaci K, Bal O, et al. Multicenter evaluation of patients with cutaneous malignant melanoma in Turkey: MELAS study. Asian Pac J Cancer Prev 2013;14(1):533-7. PUBMED | CROSSREF

4. Metelitsa AI, Dover DC, Smylie M, de Gara CJ, Lauzon GJ. A population-based study of cutaneous melanoma in Alberta, Canada (1993-2002). J Am Acad Dermatol 2010;62(2):227-32. PUBMED | CROSSREF 
5. Haenssle HA, Hoffmann S, Buhl T, Emmert S, Schön MP, Bertsch HP, et al. Assessment of melanoma histotypes and associated patient related factors: basis for a predictive statistical model. J Dtsch Dermatol Ges 2015;13(1):37-45. PUBMED | CROSSREF

6. Shoo BA, Kashani-Sabet M. Melanoma arising in African-, Asian-, Latino- and Native-American populations. Semin Cutan Med Surg 2009;28(2):96-102. PUBMED | CROSSREF

7. Cress RD, Holly EA. Incidence of cutaneous melanoma among non-Hispanic whites, Hispanics, Asians, and blacks: an analysis of California cancer registry data, 1988-93. Cancer Causes Control 1997;8(2):246-52. PUBMED | CROSSREF

8. Bellew S, Del Rosso JQ, Kim GK. Skin cancer in Asians: part 2: melanoma. JClin Aesthet Dermatol 2009;2(10):34-6. PUBMED

9. Cherobin AC, Wainstein AJ, Colosimo EA, Goulart EM, Bittencourt FV. Prognostic factors for metastasis in cutaneous melanoma. An Bras Dermatol 2018;93(1):19-26. PUBMED | CROSSREF

10. Fang S, Wang Y, Dang Y, Gagel A, Ross MI, Gershenwald JE, et al. Association between body mass index, C-reactive protein levels, and melanoma patient outcomes. J Invest Dermatol 2017;137(8):1792-5. PUBMED | CROSSREF

11. Homolak D, Šitum M, Čupić H. Clinico-pathological features of patients with melanoma and positive sentinel lymph node biopsy: a single institution experience. Acta Dermatovenerol Croat 2015;23(2):122-9. PUBMED

12. Roh MR, Kim J, Chung KY. Treatment and outcomes of melanoma in acral location in Korean patients. Yonsei Med J 2010;51(4):562-8. PUBMED | CROSSREF

13. Zitelli JA, Brown CD, Hanusa BH. Surgical margins for excision of primary cutaneous melanoma. JAm Acad Dermatol 1997;37(3 Pt 1):422-9. PUBMED | CROSSREF

14. Chevalier V, Barbe C, Le Clainche A, Arnoult G, Bernard P, Hibon E, et al. Comparison of anatomical locations of cutaneous melanoma in men and women: a population-based study in France. Br J Dermatol 2014;171(3):595-601. PUBMED | CROSSREF

15. Park KD, Lee SJ, Lee WJ, Kim DW, Chung HY, Cho BC. Clinicopathological features of cutaneous malignant melanoma. Korean J Dermatol 2007;45(2):149-58.

16. Jang HS, Kim JH, Park KH, Lee JS, Bae JM, Oh BH, et al. Comparison of melanoma subtypes among Korean patients by morphologic features and ultraviolet exposure. Ann Dermatol 2014;26(4):485-90. PUBMED | CROSSREF

17. Nam KW, Bae YC, Bae SH, Song KH, Kim HS, Choi YJ. Analysis of the clinical and histopathological patterns of 100 consecutive cases of primary cutaneous melanoma and correlation with staging. Arch Plast Surg 2015;42(6):746-52. PUBMED | CROSSREF

18. Lee WJ, Lee YJ, Shin HJ, Won CH, Chang SE, Choi JH, et al. Clinicopathological significance of tumorinfiltrating lymphocytes and programmed death-1 expression in cutaneous melanoma: a comparative study on clinical subtypes. Melanoma Res 2018;28(5):423-34. PUBMED | CROSSREF

19. Ishihara K, Saida T, Yamamoto A; Japanese Skin Cancer Society Prognosis and Statistical Investigation Committee. Updated statistical data for malignant melanoma in Japan. Int J Clin Oncol 2001;6(3):109-16. PUBMED | CROSSREF

20. Chang JW, Yeh KY, Wang CH, Yang TS, Chiang HF, Wei FC, et al. Malignant melanoma in Taiwan: a prognostic study of 181 cases. Melanoma Res 2004;14(6):537-41. PUBMED | CROSSREF

21. Kim JH, Park JH, Lee DY. Site distribution of cutaneous melanoma in South Korea: a retrospective study at a single tertiary institution. Int J Dermatol 2015;54(1):e38-9. PUBMED | CROSSREF

22. Lee MW, Koh JK, Kwon KS, Kim NI, Kim SW, Kim SN, et al. Clinical and histopathological study of cutaneous melanoma in Korea. Korean J Dermatol 2003;41(1):43-7.

23. Chi Z, Li S, Sheng X, Si L, Cui C, Han M, et al. Clinical presentation, histology, and prognoses of malignant melanoma in ethnic Chinese: a study of 522 consecutive cases. BMC Cancer 2011;11(1):85 PUBMED | CROSSREF 
24. Jung HJ, Kweon SS, Lee JB, Lee SC, Yun SJ. A clinicopathologic analysis of 177 acral melanomas in Koreans: relevance of spreading pattern and physical stress. JAMA Dermatol 2013;149(11):1281-8. PUBMED | CROSSREF

25. Lv J, Dai B, Kong Y, Shen X, Kong J. Acral melanoma in Chinese: a clinicopathological and prognostic study of 142 cases. Sci Rep 2016;6(1):31432.

PUBMED | CROSSREF

26. Wasif N, Bagaria SP, Ray P, Morton DL. Does metastasectomy improve survival in patients with stage IV melanoma? A cancer registry analysis of outcomes. J Surg Oncol 2011;104(2):111-5. PUBMED | CROSSREF

27. Barth A, Wanek LA, Morton DL. Prognostic factors in 1,521 melanoma patients with distant metastases. $J$ Am Coll Surg 1995;181(3):193-201. PUBMED

28. Palmer SR, Erickson LA, Ichetovkin I, Knauer DJ, Markovic SN. Circulating serologic and molecular biomarkers in malignant melanoma. Mayo Clin Proc 2011;86(10):981-90. PUBMED | CROSSREF

29. Sandru A, Voinea S, Panaitescu E, Blidaru A. Survival rates of patients with metastatic malignant melanoma. J Med Life 2014;7(4):572-6. PUBMED

30. Sloan AE, Nock CJ, Einstein DB. Diagnosis and treatment of melanoma brain metastasis: a literature review. Cancer Contr 2009;16(3):248-55. PUBMED | CROSSREF

31. Liu W, Dowling JP, Murray WK, McArthur GA, Thompson JF, Wolfe R, et al. Rate of growth in melanomas: characteristics and associations of rapidly growing melanomas. Arch Dermatol 2006;142(12):1551-8. PUBMED | CROSSREF

32. Sergentanis TN, Antoniadis AG, Gogas HJ, Antonopoulos CN, Adami HO, Ekbom A, et al. Obesity and risk of malignant melanoma: a meta-analysis of cohort and case-control studies. Eur J Cancer 2013;49(3):642-57. PUBMED | CROSSREF

33. Shipman AR, Millington GW. Obesity and the skin. Br J Dermatol 2011;165(4):743-50. PUBMED | CROSSREF

34. de Giorgi V, Gori A, Papi F, Grazzini M, Rossari S, Verdelli A, et al. Excess body weight and increased Breslow thickness in melanoma patients: a retrospective study. Eur J Cancer Prev 2013;22(5):480-5. PUBMED | CROSSREF

35. Skowron F, Bérard F, Balme B, Maucort-Boulch D. Role of obesity on the thickness of primary cutaneous melanoma. J Eur Acad Dermatol Venereol 2015;29(2):262-9. PUBMED | CROSSREF

36. de Giorgi V, Gori A, Grazzini M, Rossari S, Longo AS, Oranges T, et al. Obesity and melanoma. $\mathrm{Br} J$ Dermatol 2012;166(6):1357-8. PUBMED | CROSSREF

37. Kahn BB, Flier JS. Obesity and insulin resistance. J Clin Invest 2000;106(4):473-81. PUBMED | CROSSREF

38. Brandon EL, Gu JW, Cantwell L, He Z, Wallace G, Hall JE. Obesity promotes melanoma tumor growth: role of leptin. Cancer Biol Ther 2009;8(19):1871-9. PUBMED | CROSSREF

39. Pandey V, Vijayakumar MV, Ajay AK, Malvi P, Bhat MK. Diet-induced obesity increases melanoma progression: involvement of Cav-1 and FASN. Int J Cancer 2012;130(3):497-508. PUBMED | CROSSREF

40. Hutchinson PE, Osborne JE, Pringle JH. Higher serum 25-hydroxy vitamin D3 levels at presentation are associated with improved survival from melanoma, but there is no evidence that later prevailing levels are protective. J Clin Oncol 2010;28(27):e492-3.

PUBMED | CROSSREF 